\title{
A PERSPECTIVA ÉTICO-POLÍTICA NO LIVRO I DA REPÚBLICA DE PLATÃo
}

THE ETHICAL-POLICY PERSPECTIVE IN BOOK I OF THE PLATAN REPUBLIC

Cézar Cardoso de SOUZA NETO'

ISSUE DOI: $10.21207 / 1983.4225 .832$

\begin{abstract}
RESUMO
O texto apresenta a temática da importância da vida comunitária e a reflexão sobre a Justiça. Através do diálogo entre Sócrates e outras personagens, Platão demonstra o princípio de que cada membro do grupo deve cumprir sua função com maior perfeição possível. Também ressalta que a injustiça enfraquece a relação entre o cidadão e a política, gerando divergências entre o indivíduo e a comunidade. O Livro I da República trata do tema da justiça, salientando a essência e a função da justiça na alma humana.
\end{abstract}

Palavras-chave: Justiça, Platão, Virtude, Felicidade, Relativismo.

\section{ABSTRACT}

\footnotetext{
${ }^{1}$ Possui graduação em Direito (2011) e Filosofia (1997), Mestrado em Filosofia (2003) pela Pontifícia Universidade Católica de Campinas, SP., e Doutorado em Direito pela Universidade Federal de Minas Gerais UFMG, (2017), Pós-Doutorando em Direito pela USP Ribeirão Preto. Atuou como Professor de Filosofia do Direito (2013) e Lógica Jurídica (2014) no curso de Direito da Universidade Estadual Paulista Júlio de Mesquita Filho, (UNESP), Campus de Franca, SP. Também atuou como professor de Filosofia da Ciência (2013) no curso de Relações Internacionais e de Filosofia da História (2013), no curso de História, ambos na (UNESP - Campus de Franca, SP); Atuou como Assessor de Juiz, no Tribunal de Justiça de Minas Gerais (2011-2013), Vara Criminal e Execução Penal, na Comarca de S. Sebastião do Paraíso, MG. É Professor Efetivo de Filosofia e História da Secretaria de Estado da Educação de Minas Gerais, lotado na Escola Estadual Benedito Ferreira Calafiori, em S. Sebastião do Paraíso, MG. Pesquisador do Grupo de Pesquisa Internacional Cultura, História e Estado, da Universidade Federal de Minas Gerais (UFMG) e Universitat de Barcelona (UB). http://lattes.cnpq.br/0445166817190132
} 
The article presents the theme of the importance of community life and reflection on Justice. Through the dialogue between Socrates and other characters, Plato demonstrates the principle that each member of the group should perform his function with the greatest possible perfection. It also emphasizes that injustice weakens the relationship between citizen and politics, generating differences between the individual and the community. Book I of The Republic deals with the theme of justice, emphasizing the essence and function of justice in the human soul.

Keywords: Justice, Plato, Virtue, Happiness, Relativism.

\section{INTRODUÇÃO}

Platão aborda diversos assuntos que desafiavam sua realidade cotidiana e oferece conteúdos para a reflexão e a busca do Bem. Neste texto do Livro I da República² ${ }^{2}$ debate acerca da Justiça - sob perspectiva ético-política - ressalta alguns importantes pressupostos da teoria política de Platão ${ }^{3}$. A primeira parte deste texto que ora apresentamos, conta-nos a tentativa de Sócrates e de alguns interlocutores a comunicar as visões referentes à Justiça, a uma polis ${ }^{4}$ justa e, finalmente, do Bem ${ }^{5}$ e da dialética como realização no Sumo Bem.

Na República empreende-se uma busca da resolução dos problemas da polis de seu tempo, a fim de que esta não se torne vítima dos interesses particulares e, dessa forma, apresenta discussões sobre temas

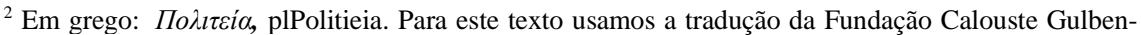
kian, $12^{\mathrm{a}}$ Edição, Lisboa, 2010.

${ }^{3}$ Platão: Nascido Arístocles, provavelmente entre os anos 429/428 em Atenas, apelidado de Platon, $\Pi \lambda \dot{\alpha} \tau \omega v$, por suas largas omoplatas. Filho da mais alta aristocracia, recebeu uma esmerada educação, tendo sido aluno de Crátilo, medíocre seguidor de Heráclito (Aristóteles, Metafísica I 6,987a32). Conheceu e se tornou amigo de Sócrates, recebendo uma grande influência deste pensador. Após a morte de Sócrates, fez uma grande viagem pela Magna Grécia, Cirene e Egito. Conheceu Díon, cunhado de Dionísio I, tirano de Siracusa, o qual vende Platão como escravo, tendo sido comprado por Anníceris que o colocou em liberdade. Regressando a Atenas, abriu a Academia, junto ao bosque de $A \kappa \alpha ́ \delta \eta \mu \varsigma \varsigma$, onde se dedicou a ensinar e a escrever suas Obras, ainda que fizesse muitas viagens, especialmente a Siracusa após a morte de Dionísio I, ajudando seu amigo Díon. Após o assassinato de Díon, não mais saiu de Atenas, oferecendo a direção da Academia a Heráclites do Ponto. "Morreu escrevendo" - Segundo Cícero - em uma comemoração, provavelmente no ano de 347. FRAILE, 1982, pp. 281-284.

${ }^{4} \pi 0 \lambda \imath \varsigma$, polis - como as antigas cidades gregas se tornaram conhecidas. Estas eram formadas pelos cidadãos (politikos), isto é, pelos homens livres, nascidos naquela comunidade. A vida na polis dividia-se em duas esferas, a privada que dizia respeito a seu patrimônio, ao casamento, à sua família e a pública, expressa pelo espaço público (político) e suas instituições nas quais se realizavam as deliberações as diretrizes e regras para a comunidade eram discutidas, aprovadas ou não, e, constituíam-se como instituições políticas. GRUBE, 1984, pp. 12-14.

${ }^{5}$ 493b-e, 505a, 507a-e.
} 
filosóficos, políticos e sociais entrelaçados em uma totalidade, tal qual a vida humana, conduzindo os mais aptos à realização do Bem.

A forma do diálogo ${ }^{6}$ empregada no texto mostra-se um elemento marcante para seu conteúdo, já que emprega uma peculiar ironia ${ }^{7}$, em meio a uma ação continuada, através da qual a mantém ativamente na memória do leitor, em uma forma de repetição do motivo.

A contribuição efetiva do Bem se mostra como fundamento na instituição da Justiça na polis, a relação entre virtude e política, educação e poder, indivíduo e comunidade, os quais se mostram necessários para a instituição de uma sociedade, regida por governantes sábios e justos. Diante da possibilidade do estabelecimento dessa polis ideal, demonstra quais seriam as condições para a sua concretização, fazendo-se necessária a compreensão e, por conseguinte, a realização da Justiça pelos membros e do caráter de seus governantes-filósofos, entendidos assim por seu conhecimento e disposição racional. Portanto, para o exercício do governo faz-se necessárias pessoas qualificadas, com conhecimentos específicos e capacidade moral.

Um traço essencial no pensamento platônico se refere à estrutura da $i_{\text {dei }}{ }^{8}$, a qual não seria simples pensamento, mas sim aquilo que o

\footnotetext{
${ }^{6}$ A forma de diálogo não é uma novidade platônica, tendo sido empregada por outros socráticos, porém, Platão é quem eleva o diálogo filosófico ao gênero literário. ROCHA PEREIRA, Maria Helena, A República, Fundação Calouste Gulbenkian, Introdução, p. VI.

${ }^{7}$ A ironia talvez seja a técnica estilística mais famosa de Platão, que se dirige a um adversário determinado. Uma ação pode estar inteiramente determinada pela ironia, caso do Eutidemo, bem como uma personagem inteira pode se mostrar sob a luz da ironia, Eutífron ou Hípias, ou a aparição de uma personagem pode ser ironicamente relativizada pelo contexto dramático, como ocorre com Alcibíades no Banquete, ou talvez até mesmo uma única reação de uma personagem que, em outros aspectos, não está mergulhada em ironia, como na capacidade de esquecimento de Adimanto com relação às limitações a que o discurso está sujeito, República IV 504 a-c. FRAILE, 1982, pp. 294-296.

${ }^{8}$ Didaticamente, Reale esclarece: “Os termos idéa $e$ éidos derivam ambos de idéin, que quer dizer 'ver', e na língua grega anterior a Platão, empregavam-se sobretudo para designar a forma visível das coisas, ou seja, a forma exterior e a figura que se capta com o olho, portanto, o 'visto' sensivel. Sucessivamente a idéa e éidos passaram a indicar, de modo translato, a forma interior, ou seja, a natureza específica da coisa, a essência da coisa. Este segundo uso, raro antes de Platão, torna-se ao invés estável na linguagem metafísica do nosso filósofo.

Paltão, portanto, fala de idéa $e$ de éidos sobretudo para indicar esta forma interior, esta estrutura metafísica ou essência das coisas, de natureza requintadamente inteligível, e usa como sinônimos os termos ousía, isto é, substância ou essência, e até physis, no sentido de natureza das coisas, realidade das coisas." REALE, 2007, p. 139.
} 
pensamento pensa quando liberto do sensível, ou seja, a essência, aquilo que faz com que cada coisa seja aquilo que é. ${ }^{9}$

Há uma correlação entre ser e conhecer, já que somente o ser se mostra cognoscível, enquanto o não ser é absolutamente incognoscível ${ }^{10}$. Porém, entre o ser e o não ser há uma categoria intermediária, que corresponde ao fazer-se, ao chegar a ser, ou seja, o ser em movimento, o qual tem algo de ser, porém, sem chegar à plenitude perfeita do ser, pois, como pergunta Platão ${ }^{11}$ como conhecer algo que não existe ${ }^{12}$

A partir do Livro $\mathrm{V}$ da República, delimita-se claramente a contraposição entre o mundo do ser, ao qual pertencem todas as realidades subsistentes, imutáveis e imperecíveis ${ }^{13}$, invisíveis ${ }^{14}$ e puras $^{15}$, que constituem o objeto da ciência suprema, a Dialética ${ }^{16}$. É o mundo das essências, das realidades existentes e conhecendo essas realidades, a alma conhece verdadeiramente o ser. ${ }^{17}$

Segundo Jaeger, é na teoria das partes da alma que desemboca a investigação do problema do que é justo, pensando nas diferentes funções da alma, nas diferentes formas que sua atividade moral adota. ${ }^{18}$

O mundo físico visível, intermediário entre o ser e o não ser, envolto em trevas ${ }^{19}$, similar a uma caverna na qual se encontram os homens como que desterrados, prisioneiros, os quais conhecem apenas o obscuro e as sombras ${ }^{20}$, imagens deformadas do mundo do ser. ${ }^{21}$

O sensível se explica mediante o recurso ao supra-sensível, o relativo com o absoluto, o móvel com o imóvel, o corruptível com o eterno $^{22}$, evidenciando que Platão concebe o complexo das Ideias como um sistema hierarquicamente organizado, no qual as Ideias inferiores impli-

\footnotetext{
${ }^{9}$ REALE, 2007, p. 140.

${ }^{10}$ Sobre a correlação entre ser e conhecer assim ensina Fraile: "los grados del conocer corresponden paralelamente em uma adecuación exacta a los grados del ser." FRAILE, 1982, p. 304.

${ }^{11} 477 \mathrm{a}$.

${ }^{12}$ FRAILE, 1982, p. 304.

${ }^{13} 485 b$.

${ }^{14} 529 \mathrm{~b}$.

${ }^{15} 573 d$.

${ }^{16}$ FRAILE, 1982, p. 329.

${ }^{17}$ Fraile ressalta que: "En el Fédon tenemos ya claramente definidas la existencia y la naturaleza de las entidades pertenecientes al mundo ideal, con caracteres contrapuestos a las del mundo físico y sensible." FRAILE, 1982, p. 328.

${ }^{18}$ JAEGER, 1994, p. 751.

${ }^{19} 508 \mathrm{~d}$.

${ }^{20} 515 \mathrm{~d}$.

${ }^{21}$ FRAILE, 1982, p. 329.

${ }^{22}$ REALE, 2007, p. 141.
} 
cam as superiores, em uma ascensão contínua até a Ideia Absoluta: o Bem. ${ }^{23}$

\section{A FUNÇÃO DA JUSTIÇA NA ALMA HUMANA}

A discussão sobre a justiça é o fundamenta deste diálogo, como se deve conduzir a vida de um modo melhor ${ }^{24}$ e de forma didática pode ser dividido em duas partes, uma primeira, em 336b a 343a, trata sobre a compreensão de justiça do sofista, e uma segunda, 343a a 354c, na demonstração socrática de que a vida do justo é melhor que a do injusto ${ }^{25}$. O debate reflete a relação do saber ético com a virtude e com a vida melhor, no qual a prática da justiça leva a uma vida de perfeição.

Com extensão considerável, o texto da República é associado ao período de maturidade de Platão ${ }^{26}$, porém, no que tange ao Livro I, traz

\footnotetext{
${ }^{23}$ Assim expõe Reale: "Sobre esse princípio incondicionado, situado no vértice, Platão se pronunciou expressamente, embora de forma incompleta, em A República, afirmando tratar-se da Ideia do Bem. E do Bem afirmou que não apenas constitui o fundamento que torna as Ideias cognoscíveis e a mente capaz de conhecer, mas que verdadeiramente 'produz o ser e a substância' e que 'o Bem não é substância ou essência, mas, firma-se acima da substância, transcendendo-a em dignidade hierárquica e em poder." REALE, 2007, pp. 141-142.

24 "Il tema di questo lavoro, la concezione della giustizia, costituisce infatti - come viene più volte sottolineato(ad es. 352d) - un nodo concettuale di importanza decisiva per rispondere alla domanda etico-politica su come si debba condurre la vita, tanto individuale quanto colletiva, nel modo migliore". VEGETTI, 2002, p. 39.

${ }^{25}$ NOVAES, 2006, pp. 119-120.

${ }^{26}$ Quanto à cronologia da Obra platônica, Fraile acompanha a divisão clássica, expondo os textos nessa ordem : Primeiro Período: diálogos de forma dramática. Da morte de Sócrates (399) à primeira viagem à Sicília (388). É o período dos diálogos aporéticos, onde as discussões não levam à conclusões expressas, mas ressalta o propósito apologético da reabilitação da figura de Sócrates. São atribuídos a este período: Apologia de Sócrates; Crítion; Laques; Híppias menor; Górgias; Alcibíades; Ménon; Íon; Híppias maior; Crátilo; Eutífron; Trasímaco (Livro I da República).

Segundo Período, também conhecido por Transição: da fundação da Academia (387) à segunda viagem à Sicília (366-365). Mostra-se maduro, demonstra seus próprios conceitos, revelando sua profunda abstração com estilo depurado. Fraile associa o leve matiz pessimista à experiência em Siracusa. Nesta fase, combate os conceitos defendidos pelos sofistas. Atribuem-se a este período, cujos textos são divididos em: diáologos de forma narrativaProtágoras; Lisis; Eutidemo; Cármides; Clitofón; Banquete; Fédon; República; diáologos de forma mista (transição à forma dramática): Menexeno; Fedro; Teeteto; Parmênides.

Terceiro Período (entre a segunda e terceira viagem à Sicília): Sofista; Político;

Quarto Período (também chamado de "velhice", onde se observa bastante pitagorismo, que ocorre depois da terceira e última viagem à Sicília até sua morte em 347): Filebo; Timeu; Crítias; Carta VII e Leis. FRAILE, 1982, pp. 284-292.

Fraile também oferece algumas das diferentes análises sobre a cronologia da Obra Platônica:

"W.G. Tennemann expuso em forma sistemática el pensamiento platónico, acomodándolo a su próprio concepto de la Filosofia. Introdujo el supuesto período megárico, en el cual ponía la composi-
} 
consigo a dúvida se fora uma obra independente e só mais tarde "retocado" para servir como proêmio ${ }^{27}$ à República, ou se de fato, fora escrito como parte integrante da obra.

A questão do termo proêmio, usado logo no início do Livro II, possibilita relacionar este primeiro livro ao conjunto dos diálogos aporéticos caracterizados como pertencentes à primeira fase dos escritos de Platão, nos quais propõe uma definição de uma virtude ${ }^{28}$. Um dos mais respeitados especialistas, Paul Friedländer ${ }^{29}$, aprofundando as pesquisas e discussões iniciadas no séc. XIX, tal como Dümmler, Schleiermacher e Hermann já haviam notado, observa as relações deste Livro com os primeiros diálogos, onde irá denominar este Livro I como Trasímaco, nome do sofista interlocutor de Sócrates. ${ }^{30}$

O Livro I exerce perfeitamente o mister introdutório da República, visando refletir a definição de Justiça a partir da relação entre esta e a virtude, como fatores essenciais na constituição de ordem, sanando os conflitos entre limitadas noções de justiça e a aplicação da Justiça na arte

ción del Teeteto (System der Platonische Philosophie, Leipzig 1792-1795). G. Stallbaum (1831), H. Ritter (1824-1854), G.F. Hermenn (1839) y Zeller admiten también el período megárico, que carece de todo fundamento.

F. Scheiermacher señala um orden pedagógico dividido em tres períodos: $1^{\circ}$, elemental, directo (Fedro, Protágoras, Parmênides); $2^{\circ}$., indirecto, por medio de la discusión (Teeteto, Sofista, Político, Banquete, Filebo); $3^{\circ}$., constructivo, por medio de la exposición objetiva (República, Timeo, Leyes). (Platon's Werke, Berlin 1804, 1856-1862).

G.F.Hermann distingue tres períodos: $1^{\circ}$. Socrático, $2^{\circ}$. Megárico (Crátilo, Teeteto, Sofista, Político, Parménides); $3^{\circ}$. Constructivo, o de madurez (Fedro, Filebo, Timeo, Critias, Leyes) (Geschichte und System der Platonischen Philosophie, Heidelberg 1839).

V.Cousin señala tres fases: $1^{a}$. Mística o poética; $2^{a}$. Dialética o racional; $3^{a}$. Mixta, en que se mezclan el sentimiento y la razón (Oeuvres completes de Platon, Paris 1821-1840).

$G$. Grote considera que cada diálogo constituye uma composición independiente, sin ninguna intención sistemática (Platô and the ordercompanions of Sokrates, Londres 1867).

G. Teichmüller adoptó um criterio interno, distribuyendo los Diálogos en dos períodos, caracterizados por el empleo de la forma narrativa y la dramática." FRAILE, 1982, pp. 285-286 (notas).

${ }^{27}$ Empregado nesta tradução como prelúdio: $357 \mathrm{a}$.

28 “(...) virtude, que vai sendo substituída por outras, à medida que Sócrates demonstra a sua insuficiência; de modo que, quando termina a discussão, a conclusão é negativa. Assim, o Lísis falha em definir a amizade, o Cármides a temperança (sophrosyne), o Laques a coragem, o Êtifron a piedade. A coragem, a temperança, a piedade formavam com a justiça o grupo das virtudes cardeais, já esboçado desde Ésquilo e Píndaro, pelo menos. Ora, definir a justiça é o que tenta fazer, sem conseguir, o Livro I da República. Seria esse o livro que faltava, para completar o conjunto, pois não era de supor que Platão, que durante o período dos diálogos aporéticos, investigou todas as virtudes, omitisse esta." ROCHA PEREIRA, Introdução, pp. XVIII-XIX.

${ }^{29}$ FRIEDL ̈̈NDER, Paul. Plato. New York: Pantheon Books, 1979.

${ }^{30}$ ROCHA PEREIRA, Introdução, pp. XIX-XX. 
de governar, congregando-o junto às outras três obras-primas do período da maturidade platônica: Banquete, Fédon e Fedro. ${ }^{31}$

Platão inicia sua obra a partir do problema da justiça ${ }^{32}$, uma vez que essa virtude política resumiria todas as outras virtudes ${ }^{33}$. Dessa forma, na busca pela definição de justiça, o que está em pauta é a estrutura política vigente em Atenas, para a qual as teses apresentadas por Tra$\operatorname{símaco}^{34}$ oferecem contribuições para serem discutidas e refutadas, já que têm sua base em uma argumentação na qual a justiça não seria nada mais que reforçar o poder dos fortes contra os fracos, como fazem os tiranos, com suas leis autoritárias. ${ }^{35}$

Sócrates nos convida a investigar, de maneira reflexiva qual seria a correta definição de Justiça, em um conceito mais amplo, que pudesse abranger a totalidade. ${ }^{36}$

O conceito platônico de justiça começa a se mostrar muito além daquele que fora apresentado pelo sofista, pois se eleva acima das normas humanas, remontando até as suas origens, na própria $\mathrm{alma}^{37}$, uma vez que a justiça deve possuir um significado muito mais profundo que a mera obediência às leis da polis ${ }^{38}$.

De acordo com a concepção platônica, uma política que se estruture apenas nas leis de dimensão material do ser humano, negando ou reprimindo as exigências espirituais, estará fadada ao fracasso, já que as realidades espirituais virão a se impor novamente ${ }^{39}$, portanto, a justiça tem de ser inerente à alma, já que Platão coloca em relevo a essência e a função da justiça na alma humana ${ }^{40}$.

A política autêntica fundamenta-se no bem do ser humano, porém, como bem espiritual, já que o corpo não passa de um invólucro efê-

\footnotetext{
${ }^{32}$ JAEGER, 1994, p. 755.

${ }^{33}$ Ibd., p. 755. vol. I p. 237; BURN, 2007, p. 11.

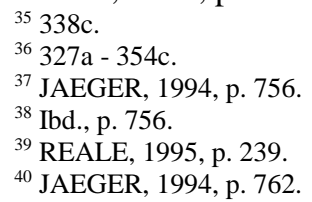

${ }^{31}$ ROCHA PEREIRA, Introdução, pp. XX-XXI.

34 Trasímaco nasceu na Calcedônia, na Bitínia, por volta de 459 a.C. Reale,1993,

"Muy probablemente sus obras parecen haber sido Discursos deliberativos y un Tratado de retórica, de los cuales nos restaron pocos fragmentos." BLACK- 
mero, portanto, a verdadeira política deve encarregar-se do bem da alma. 41

\section{TRASÍMACO E OS SOFISTAS: ENTRE $O$ RESSENTIMENTO E A CRÍTICA}

A crítica platônica aos sofistas, que muitas vezes ultrapassa os limites da ironia crítica para a difamação, foi bastante eficaz para a caracterização infame que estes sábios receberam no decorrer da História do pensamento ocidental ${ }^{42}$. Para Jaeger ${ }^{43}$, o filósofo ateniense traz em suas críticas um traço do ambiente social aristocrático no qual fora formado, uma vez que a maioria dos sofistas era composta de metecos ${ }^{44}$ que necessitavam de dinheiro para sobreviver em Atenas, o que lhes fazia necessário cobrar por suas aulas.

Ao empregar o relativismo, iniciado por Protágoras de Abdera, os sofistas passaram a utilizar a erística, técnica de disputa argumentativa num debate filosófico, visando unicamente vencer uma discussão, porém, não busncando descobrir a verdade de uma questão, tornando-se assim um dos principais argumentos platônicos em suas críticas aos sofistas. ${ }^{45}$

Encontramos no Livro VI da República como a figura dos sofistas é escarnecida, seja em 492a como corruptores da juventude, seja em 493a a ácida crítica entorno da cobrança pela educação, já que, segundo Platão, eles não passavam de mercenários. Dessa forma, acabou por relegar à posteridade um mau conceito daqueles que eram considerados sábios na sociedade grega, ressaltando apenas o negativo entre os sofistas,

\footnotetext{
${ }^{41}$ REALE, 1995, p. 238.

${ }^{42}$ Interessante o que conclui Reale: "a responsabilidade máxima de desacreditar os sofistas foi de Platão, e o foi, menos pelo conteúdo, e mais pelo modo particularmente eficaz como disse." REALE, 1993, vol. I, p. 190.

${ }^{43}$ JAEGER 1994, p. 364.

${ }^{44}$ MÉtolкоৎ estrangeiros que residiam nas poleis gregas, particularmente importantes em Atenas. Não tinham direitos políticos e nem podiam se casar com cidadãos. Pagavam taxas para viver e trabalhar em Atenas. Homens livres podiam participar do serviço militar. Geralmente se dedicavam ao comércio e aos serviços. GRUBE, 1984, p. 14.

45 "Platón al utilizarse del término erística, críticamente se refiere al método desarrollado por los sofistas que propone como único objetivo la victoria en la discusión, recurriendo a la argumentación sutil y a los elementos de retórica a su alcance, lo cual es totalmente contrario a la dialéctica, que es el verdadero arte de la investigación y del diálogo que busca el conocimiento de la verdad." MELLING, 1992, p. 87.
} 
olvidando-se da face positiva e autêntica da sofística representada por Sócrates. ${ }^{46}$

Platão oferece uma visão negativa de Trasímaco ${ }^{47}$, bem como de todos os sofistas, considerando-lhes como falsos e formadores de raciocínios capciosos, reprovando a atitude de ensinarem mediante pagamento. ${ }^{48}$

Assim sendo, apresenta no diálogo a figura de Trasímaco, como mestre de retórica, desejando falar, querendo exibir sua sabedoria ${ }^{49}$. Esta personagem seria um especialista em longos discursos, capaz de inundar com a sua caudalosa eloquência ${ }^{50}$, como uma fera capaz de dilacerar ${ }^{51}$, e

\footnotetext{
${ }^{46}$ REALE, 1993, vol. I, p. 239.

47 "Trasímaco no es el inmoralista que quieren algunos estudiosos, sino un representante
}

de una opinión general. Él ha pasado a ser considerado un belicoso sofista que representa la filosofía del poder de Cálicles. Esta coincidencia de rasgos en los sofistas no es um mero accidente, pues, Trasímaco se entiende mejor en el marco de la tradición relativista, cuyo exponente más destacado es el sofista Protágoras de Abdera, el máximo representante del relativismo. Platón pone en boca de Trasímaco una teoría de la justicia que generalmente ha sido interpretada junto a las líneas de las teorías propuestas por los sofistas (como la de Cálicles en el Gorgias), tipicamente relativistas y, consecuentemente, que hacen apología de la injusticia. Hay que notar que se mostran muy claras dos lineas de argumentación, entre Trasímaco y Platón. En lo que se refieren a la justicia debe entenderse: una como realidad absoluta, establecendo la perfección moral como una totalidad, pues, el bien moral es la felicidad, de la que nadie se aparta por su propia voluntad, pues se llega al Bien, tesis platônica; otra, comprender la justicia como una relación, lo que lleva a la tirania de la voluntad de aquellos que detienen el poder, tesis de Trasímaco y de toda una tradición relativista." MELLING, 1992, pp. 86-87.

48 Também encontramos neste trecho da Obra Sofista a concepção platônica em relação ao ensino dos sofistas: "Em primeiro lugar, o sofista era um caçador remunerado de jovens ricos [...]; em segundo lugar uma espécie de importador de conhecimentos que interessam à alma [...] e em terceiro lugar, não se nos mostrou como um biscateiro destas mesmas coisas? [...] e em quarto lugar, um mercador dos próprios produtos aplicados aos discursos, como quem tivesse reservado para si a arte de disputar [...] depois, em sexto lugar, era algo de controvertido, todavia é preciso admitir que ele seja uma espécie de purificador espiritual das opiniões que impedem a alma de saber". (Sofista, 231d-231e) Fundação Calouste Gulbenkian, Edição, Lisboa, 2012.

${ }^{49} 338 \mathrm{a}$.

${ }^{50} 344 d$. 
uma serpente capaz de matar um homem indefeso e inocente ${ }^{52}$, uma vez que encarna o que há de mais repugnante: o sofista ${ }^{53}$.

Nesse sentido, o filósofo ateniense descreve que Trasímaco considerava seu mestre Sócrates como um simplório ${ }^{54}$ que busca tornar-se célebre $^{55}$, o qual evidencia sua arrogância sofística, mostrando-se aborrecido com Sócrates e pergunta-lhe se deseja que coloque o diálogo travado sobre Justiça dentro de sua cabeça. ${ }^{56}$

Trasímaco é descrito como o modelo do homem ganancioso que deseja cobrir-se de glória ${ }^{57}$, muito diferente do homem simples, honesto e inocente apresentado na figura de Sócrates, evidenciando-se isso quando ele salta, feito um lobo ou uma serpente, no meio da discussão sobre a justiça e tenta impor o seu conceito sobre este tema causando susto entre os presentes. ${ }^{58}$

Esse desprezo de Platão pelos sofistas traz consigo alguns questionamentos que nos parecem de difícil resolução.

Reale $^{59}$ nos lembra que Atenas passava por uma crise, onde membros do demos $^{60}$ passaram a exercer, cada vez mais, importantes

$51336 \mathrm{~b}$.

$52358 \mathrm{~b}$.

${ }^{53} \sigma o ́ \phi \imath \sigma \mu \alpha-\alpha \tau o \varsigma$, derivação de $\sigma o \phi i \xi \xi \sigma \vartheta \vartheta \alpha$ - aquele que faz raciocínios capciosos. Foram mestres itinerantes, viajando de polis em polis, considerados sábios na Grécia Antiga. Tiveram grande importância em Atenas ao se dedicarem à educação de jovens aristocratas e cidadãos para exercerem atividades políticas. Eram hábeis oradores, propunham ensinar qualquer coisa aos cidadãos que almejassem um cargo na polis, ou que se defenderiam nos casos litigiosos. Exerciam admiração naqueles que os ouviam, transformando um fraco argumento em um forte e vice-versa. Propunham o conhecimento e o convencimento através da oratória. Recebiam salário pela atividade de ensino. Considerados como os dois maiores sofistas de todos os tempos, Protágoras e Górgias foram figuras ilustres dentre os sofistas, sendo também destacados, em Atenas, estão Híppias, Pródico, Antístenes, Trasímaco. GRUBE, 1984, pp. 16-18.

${ }^{54} 336 \mathrm{~b}$.

$55336 \mathrm{c}$.

${ }^{56} 345 \mathrm{~b}$.

${ }^{57} 338 \mathrm{a}$.

58 336b-336d.

${ }^{59}$ REALE,1993, p. 193.

${ }^{60} \delta \dot{\eta} \mu o \varsigma$ originalmente uma subdivisão da Ática, na região do entorno de Atenas. Existentes como meras subdivisões das áreas agrícolas e pastoris, passaram a adquirir uma maior importância a partir das reformas de Clístenes, 507/509 a.C., obrigando o alistamento nas listas de cidadãos de cada demo para que se obtivesse a cidadania, que era obtida pela associação a uma fratria, ou seja, um grupo familiar. Concomitantemente, os demos foram criados em Atenas, enfraquecendo assim os genoi, as 
funções administrativas, o que acabou gerando questionamento e crise do modelo social baseado na sociedade aristocrática.

Jaeger chama de "crise da aretê", esse momento no qual o predomínio da aristocracia, que acreditava que fora designada pelos deuses a governar a polis, começava a dar espaço político, cada vez maior, para membros dos demos. ${ }^{61}$

Os sofistas têm sua participação nessa mudança, uma vez que passam a ensinar não somente aos aristocratas bem como aos membros do demos, e, possibilitando o acesso destes aos círculos de discussão política, e são extremamente necessários para o estudo da filosofia, já que sem eles, Sócrates e Platão seriam impensáveis. ${ }^{62}$

Dessa forma, acabaram criando o que Reale chamou de iluminismo grego ${ }^{63}$, ensinando a todos aqueles que pudessem pagar, levando muitos cidadãos que não eram membros da aristocracia à ascensão social.

\section{FORTE OU JUSTO, EIS A QUESTÃO}

Sócrates dá início ao diálogo, dirigindo-se ao anfitrião e perguntando-lhe o valor da velhice, o qual the responde que menos pesada se caso chegasse a ela sem que nada fosse devido a alguém. O perguntador loquaz agora lhe questiona acerca das riquezas, da herança, cuja resposta leva a uma concepção de justiça como falar a verdade e restituir aquilo que se tomou. ${ }^{64}$

Polemarco, o herdeiro, assume o lugar do pai na sequência do diálogo, definindo a Justiça como dar a cada um aquilo que lhe é devido ${ }^{65}$ e, com suave ironia, vê-se refutado por Sócrates, seguindo a afirmação do jovem herdeiro que então a justiça seria favorecer os amigos e prejudicar os inimigos ${ }^{66}$, sendo portanto rebatido por Sócrates. ${ }^{67}$

famílias aristocráticas que exerciam o domínio das fratrias e, por conseguinte, da política ateniense. GRUBE, 1984, pp. 14-16.

61 JAEGER, 1994, p. 341.

62 JAEGER, 1994, p. 503.

${ }^{63}$ REALE, 1993, vol. I, p. 197.

${ }^{64} 331 \mathrm{~b}$.

$65331 \mathrm{e}$.

${ }^{66} 332 \mathrm{a}$.

${ }^{67} 335 \mathrm{e}$. 
Depois de Trasímaco oferecer sua célebre noção de justiça, como conveniente ao mais forte ${ }^{68}$, ambos os interlocutores, têm uma clara consciência do tipo de diferenças que lhes distanciam, iniciando o debate.

Sócrates, então, argumenta que esta noção de equivalência entre mais forte e governo estabelecido, estaria baseada no erro, já que o forte determinaria aquilo que entende como mais conveniente aos seus interesses.

Trasímaco, ainda que refutado pelo filósofo, sustenta que o governante, enquanto tal, não erraria, reafirmando sua posição inicial ${ }^{69}$. Sócrates emprega a analogia com as técnicas, sendo replicado pelo sofista com o exemplo do pastor, o que lhe dá a oportunidade para introduzir a noção tradicional da justiça como bem alheio ${ }^{70}$, reafirmando esta noção, mas, especificando quem seria o outro, receptor do bem, ou seja, o forte.

Segundo essa concepção que pretende analisar a vida social com uma teoria que se baseia em termos relacionais, o bem que fazemos aos outros seria compensado com o que os outros nos fariam, assim, os fortes seriam sempre receptores do bem alheio e nunca doadores. ${ }^{71}$

Sócrates refuta a noção relativista de Trasímaco com a perspectiva de oferecer uma noção não relativa de justiça, pois, a justiça já não seria fazer bem a uns e mal a outros, porém, somente fazer o bem.

Pode-se compreender que o justo faz o bem em todas as circunstâncias e a todos com os quais se relaciona, pois não se entenderia

\footnotetext{
${ }^{68} 338 \mathrm{c}$.

${ }^{69} 341 \mathrm{a}$.

$70343 b$.

71 “El análisis platónico incluye dos movimientos: primero, se muestra el carácter relativista

de dicha noción para descubrir las contradicciones que implica. En un segundo movimiento, se

ofrece una noción alternativa consistente en la propuesta de una noción no relativa de justicia. En este proceso debemos anotar dos cuestiones que aparecerán en el escenario siguiente, el de la disputa con Trasímaco:

a) la oposición entre ser y parecer amigos o enemigos. De otro modo, la oposición entre los que en verdad son amigos y los que uno considera que son amigos. Este mismo problema se plantea después con la posible oposición entre lo que es conveniente y lo que parece conveniente.

b) la discriminación entre el ser y el aparecer está siempre sujeta al riesgo del error. Esta cuestión se corresponde en el segundo escenario con el problema de la infalibilidad del gobernante." BLACKBURN, 2007, p. 66.
} 
que fazer o bem não tivesse um destinatário definido no tempo e no espaço.

Dessa forma, o que se afirma no argumento platônico é o caráter universal da conduta do justo, assim, aquele que possui o poder, utilizaria em benefício dos governados ${ }^{72}$.

\section{$5 \quad$ CONCLUSÃO}

O sentido moral de justiça apresentado por Trasímaco, mostrase muito próximo da ideia de normas impostas por um governante, obrigatórias e coercitivas, uma justiça como conveniência do mais forte ${ }^{73}$, como uma equivalência entre justo e legal. Tendo como finalidade apresentar a discussão acerca da Justiça, o Livro I, cumpre sua finalidade, analisando as diversas definiçõos expostas desde aquelas apresentadas pelo idoso Céfalo ${ }^{74}$, pelo jovem Polemarco ${ }^{75}$ e pelo importante sábio Trasímaco $^{76}$, discutidas com o ainda desconhecido e simplório Sócrates, um sofista questionador, que ainda irá tornar-se célebre. ${ }^{77}$

Assim, tudo aquilo que pudesse ser considerado legal, por meio de uma Lei, outorgada por um governante, seria justo, simplesmente por estar de acordo com a vontade daquele que exerce o poder.

Ao aprofundar o diálogo, Sócrates, demonstra que a justiça não se refere apenas àquilo que seja útil, baseado numa concepção relativista, provando que aquilo que o sofista tinha como justiça, não passava de mera opinião, carecendo de fundamento, a qual não tem um caráter universal.

A justiça se baseia no princípio em virtude do qual cada membro do organismo social deve cumprir com maior perfeição possível, sua função própria. ${ }^{78}$

As leis seriam os preceitos estabelecidos por Platão para o governo de sua comunidade, porém, tais leis versam todas exclusivamente

\footnotetext{
$72345 \mathrm{e}$.

${ }^{73} 338 \mathrm{c}$

${ }^{74} 331 \mathrm{~b}$.

$75331 \mathrm{e}$.

${ }^{76} \mathrm{Ibd}$.

77 336c.

${ }^{78}$ JAEGER, 1994, p. 806.
} 
sobre a estrutura da educação ${ }^{79}$, pois, a justiça é a saúde da alma, sempre que concebemos esta como o valor moral da personalidade ${ }^{80}$. Dessa forma, ao se mostrarem aptas para a busca da felicidade eterna (beatitude), as leis, as instituições sociais e a educação mostram-se justas ${ }^{81}$, pois, formar o verdadeiro Estado é formar o verdadeiro homem. ${ }^{82}$

A injustiça enfraquece a relação entre o cidadão e a política, gerando divergência dentro de si mesmo ${ }^{83}$, bem como entre o indivíduo e a polis ${ }^{84}$, tratando do tema da justiça como um meio para um fim, por em relevo a essência e a função da justiça na alma do homem. ${ }^{85}$

Uma das raízes da vontade platônica que impele o homem para a comunidade política é a consciência de que o homem não prospera isoladamente, mas somente no interior de um mundo circundante adequado ao seu ser e ao seu destino ${ }^{86}$. De forma irônica, gratuita e humilde, a intervenção de Sócrates é sábia: governar é estar a serviço dos governa$\operatorname{dos}^{87}$, como um médico curando os doentes ${ }^{88}$, afinal, a justiça é superior à injustiça e é preferível sofrer a injustiça que praticá-la. Portanto, onde se pratica a injustiça, aí está a desunião e a discórdia. Onde houver justiça, aí está a felicidade ${ }^{89}$, pois a felicidade é o fruto da justiça.

\section{REFERÊNCIAS BIBLIOGRÁFICAS}

BLACKBURN, Simon. Historia de la República de Platón. Madrid: Debate, 2007.

CROISET, Maurice. La République de Platon. Paris: Éditions Mellotée, 1946.

CROMBIE, I.M. Análisis de las doctrinas de Platón. Madrid: Alianza Editorial, 1990.

FRAILE, Guillermo. Historia de la Filosofia. Vol I. Madrid: BAC, 1982.

FRIEDLÄNDER, Paul. Plato. New York: Pantheon Books, 1979.

\footnotetext{
${ }^{79}$ Ibd., p. 808.

${ }^{80} 444 \mathrm{c}-\mathrm{e}$.

${ }^{81}$ JAEGER, 1994, p.

${ }^{82}$ JAEGER, 1994, p. 791.

${ }^{83} 352 \mathrm{a}$.

${ }^{84} 351 \mathrm{c}$.

${ }^{85}$ JAEGER, 1994, p. 762.

${ }^{86}$ Ibd., p. 792.

$87345 \mathrm{e}$.

${ }^{88} 341 \mathrm{c}$.

${ }^{89} 354 \mathrm{a}$.
} 
GRUBE, G.M.A., El pensamiento de Platón. Madrid: Gredos, 1984.

JAEGER, Werner. Paidéia. A formação do Homem Grego. São Paulo: Martins Fontes, 1994.

MELLING, David J. Introducción a Platón. Madrid: Alianza Editorial, 1992.

MORA, José Ferrater. Diccionario de Filosofía. Vol. IV. Barcelona: Ariel, 2009.

NOVAES, Roberto Vasconcelos, O Filósofo e o Tirano, por uma teoria da Justiça em Platão. Belo Horizonte: Editora Del Rey, 2006.

PLATÃO. A República. Introdução, Tradução e notas de Maria Helena da Rocha Pereira, $12^{\mathrm{a}}$ Edição, Lisboa: Fundação Calouste Gulbenkian, 2010.

. O Sofista. Tradução de Juvino Maia Jr., Henrique Murachco e José Trindade Santos. $1^{\text {a }}$ Edição, Lisboa: Fundação Calouste Gulbenkian, 2012.

REALE, Giovane. História da Filosofia Antiga. Vol 1.e Vol. 2. São Paulo: Loyola, 1993.

História da Filosofia. Filosofia pagã antiga. Vol. 1. $3^{\mathrm{a}}$ ed., São Paulo: Paulus, 2007.

SZLEZAK, Thomas A. Leer a Platón, Madrid:Alinza Editorial, 1997.

VIGETTI, Mario. Guida alla lettura della Republica di Platone. Roma: Laterza, 2002. 